\title{
EDUCATION AND TRAINING Pharmacology for physician associate programmes: a collaborative, flexible and responsive approach to curriculum design
}

\author{
Authors: Brogan N Guest, ${ }^{A}$ Chanceeth Chandrakanthan, ${ }^{B}$ Kate Bascombe ${ }^{C}$ and Jeannie Watkins ${ }^{D}$
}

There are more than 2,000 physician associates (PAs) in the UK working in general practice and secondary care, and that number is growing. The NHS estimates that there will be over 5,900 PAs in the UK by the end of 2023. Currently, PAs in the UK are unable to prescribe medication due to the absence of statutory regulation and the necessary prescribing legislation. The Department of Health and Social Care, with the support of the four UK governments, recently announced the introduction of statutory regulation of medical associate professionals, which includes PAs. The General Medical Council will be the statutory regulator. A working group is now considering prescribing authority, scope of practice, education training and delivery, and how this will be achieved. At St George's, University of London, we teach applied pharmacology as part of the core curriculum for PAs.

KEYWORDS: physician associate, applied pharmacology, drug formulary, prescribing, education

DOI: 10.7861/fhj.2021-0099

\section{Introduction}

Physician associate (PA) programmes are a minimum of 90 weeks with a mixture of theory and clinical practice. After graduation, students are awarded a Master of Science (MSc), Master of Physician Associate Studies (MPAS) or postgraduate diploma (PGDip), depending on the programme. ${ }^{1}$ At St George's, University of London (SGUL), the first year of the PA programme is mostly didactic with students attending general practice (GP) placement weekly. In their second year, students attend clinical placements

Authors: Aphysician assistant and lecturer, St George's, University of London, London, UK; ${ }^{\text {B }}$ physician associate and lecturer, St George's, University of London, London, UK; ' physician associate and senior lecturer, St George's, University of London, London, UK; ' D physician associate and reader, St George's, University of London, London, UK with occasional didactic teaching. Students at SGUL undertake several modules including Foundations of Clinical Medicine (FCM), Investigations of Clinical Medicine (ICM), Applied Pharmacology (AP), Personal and Professional Development (PPD), EvidenceBased Medicine, and Applied Clinical Knowledge and Skills. On successful completion of the PA programme, students at SGUL are awarded an MPAS.

All PA students are required to pass the national certifying examination to enter professional practice. The national certifying exam is based on the Competence and Curriculum Framework (CCF) and Matrix of Core Clinical Conditions that was released by the Department of Health in 2006 and revised in 2012. ${ }^{2}$

Currently, PAs are not legally permitted to prescribe in the UK although, in their day-to-day roles, more than $70 \%$ of PAs report managing acute, emerging and chronic conditions. They do this through their close collaboration with supervising physicians. PAs may often 'prepare' prescriptions for signature by a supervising physician. $^{3}$

With the introduction of statutory regulation of PAs through the General Medical Council (GMC), we anticipate discussion of whether PAs should be given prescribing rights upon passing the national certifying exam or whether they will require additional independent prescribing training, assessment and supervision. 3,4 We also anticipate further education guidance to be released by the GMC and possible quality assurance audits.

We used this opportunity to review the AP module to ensure it was fit for purpose and likely to withstand upcoming review by the GMC for quality assurance.

We considered student feedback from previous terms, which highlighted a consistent theme of too strong a focus on basic pharmacology and not enough pharmacotherapeutics. We used the student feedback, collaboration with the clinical pharmacology department at SGUL and our experience working as PAs to re-design the module with a stronger focus on pharmacotherapeutics and the application of pharmacology principles.

The COVID-19 pandemic also necessitated significant shifts in the delivery of teaching across higher education. This module transitioned from fully face-to-face teaching to remote delivery with a focus on utilising technology to enhance the student experience while ensuring it was rigorous enough to teach students safe prescribing. 


\section{Challenges faced in teaching pharmacology} to PA students

Teaching pharmacotherapeutics and pharmacology presents several challenges for PA schools. Firstly, in the UK, students may find it difficult to appreciate the relevance of the module when they are not legally permitted to prescribe on graduation. As this is a relatively new career, students may not understand how PAs will use pharmacology knowledge to propose prescriptions and monitor treatment plans. They may also not realise the significant role that medications can play in the causation of patients' symptoms and the importance of identifying this when taking a patient history.

Secondly, before students can understand how to apply pharmacology to patients and to safely prescribe, they must learn a base-level of medication knowledge. Most students enter PA programmes with little medication knowledge. In our 2020-2021 cohort, only six students (10\%) came from healthcare backgrounds and one (1.67\%) from pharmacology. Teaching mechanism of actions, indications, contraindications, interactions and side effects of medications is not easily done. The material is dense and can be difficult to make engaging.

The largest challenge in teaching pharmacology is determining what breadth and depth PAs need to know: which drugs are imperative for students have knowledge of, should they learn class and drug names, and do they need to learn doses. The goal of the national qualifying examination is to determine whether PAs are safe and competent to practise. The PA national examination blueprint states that $40 \%$ of the qualifying examination covers managing patients including clinical interventions and therapeutics. ${ }^{5}$ However, there is little guidance on the level of required pharmacology knowledge for PAs. In conjunction with the CCF, the Matrix of Core Clinical Conditions identifies which conditions PAs can be expected to diagnose and/or manage independently. ${ }^{5}$ We faced some difficulty when using the matrix to deduce required pharmacology knowledge.

\section{Our approach to teaching pharmacology}

With a focus on the aforementioned challenges and student feedback, we redesigned the MPAS AP module with a focus on increasing clinical relevance, encouraging self-directed learning (SDL) and assessing higher-level application of knowledge. We recognise the importance of relevance in teaching, fostering lifelong learning through SDL and of assessing practical clinical skills. ${ }^{6}$ This was under the umbrella of utilising technology to bring the module into the remote learning era.

When reviewing the module and its fitness for the future, we referred to the V300 Independent/Supplementary Prescribing Programme, a 6-month course designed for nurses, midwives and allied healthcare professionals. ${ }^{7}$ We aimed to align the module with the intended learning outcomes closely resembling the V300 programme, a programme designed to teach safe prescribing. The aim of the course is to enable students to demonstrate all the competencies outlined in the Royal Pharmaceutical Society's $A$ Competency Framework for all Prescribers. ${ }^{8}$

\section{Module relevancy}

As PAs are unable to prescribe after qualification, we are aware that, initially, our students may find it difficult to recognise the relevance of the AP module. To address this in the first session, two PAs (one working in primary care and one in secondary care) meet with the students and discuss how they use AP knowledge in their day-to-day practice: reviewing patients who are on medications, considering whether patients' symptoms could be related to drug side effects, proposing new medication prescriptions and discussion with a GP supervisor prior to them signing the scripts.

Likewise, we explain how AP knowledge is useful in other modules because of our curriculum alignment. While the students are learning cardiovascular anatomy, pathology and investigations, the AP module concurrently focuses on medications used to manage hypertension and heart failure, for example. ${ }^{9}$

\section{Module content}

One of the most difficult things to address in an AP module is the balance of emphasis on basic pharmacology knowledge versus clinical pharmacology knowledge. The potential breadth for pharmacology teaching is wide; students should understand the principles of bioavailability and must also recognise that, for example, lisinopril is contraindicated in pregnancy. We worked with the SGUL clinical pharmacology team to design a curriculum where $70 \%-80 \%$ focused on clinical pharmacology and $20 \%$ $30 \%$ on basic pharmacology and prescribing principles: drug delivery, medicine and the law, how to write a prescription, and drug dose calculation. All the lectures and learning objectives bring focus on clinical application of knowledge (see learning objectives in supplementary material S1).

\section{Drug formulary}

Although our goal was to bring a stronger focus to clinical application of pharmacology, students first needed a foundational level of medication knowledge. Within weeks of starting the programme, our students are seeing patients in a GP clinic, proposing treatment plans for case studies and learning to understand and apply National Institute for Health and Care Excellence (NICE) treatment guidelines.

We decided against teaching about medications in lecture format and instead introduced an SDL component in the form of a drug formulary. Their drug formulary will include any drugs they see commonly in their learning and on their GP placements. In the first lecture, students were introduced to details on what a formulary should contain: indications, contraindications, side effects (common and life threatening), interactions, monitoring and mechanism of action. The students are encouraged to create their formulary electronically and continue to build their formulary throughout their 2 years of PA school. This self-regulated learning aligns with the objectives of the $\mathrm{V} 300$ course, which requires students to build a formulary specific to their field and is a lifelong skill for clinical practice.,

In addition to the formulary, students are given a core drug list. The core drug list includes approximately 70 drugs and was derived from the PA Matrix of Core Clinical Conditions and was compiled with a team of PAs and a clinical pharmacologist (Table 1). This is a list of drugs the students will likely come across in their training and should have some familiarity. There will be considerable overlap between the core drug list and their formulary. The core drug list guides their revision, as the majority of assessment questions will be based on the core drug list. 
Table 1. Core drug list for physician associates

\begin{tabular}{|c|c|c|}
\hline System & Core drugs & Nice to know \\
\hline Cardiovascular & $\begin{array}{l}\text { Aspirin } \\
\text { Clopidogrel } \\
\text { Statins } \\
\text { Warfarin } \\
\text { Heparin } \\
\text { Direct oral anticoagulants } \\
\text { Loop diuretics } \\
\text { Angiotensin receptor } \\
\text { blockers } \\
\text { Beta blockers } \\
\text { Alpha blockers } \\
\text { Thiazide diuretics } \\
\text { Calcium channel blockers } \\
\text { Angiotensin converting } \\
\text { enzyme inhibitors } \\
\text { Mineralocorticoid } \\
\text { receptor antagonists } \\
\text { Nitrates }\end{array}$ & Digoxin \\
\hline Respiratory & $\begin{array}{l}\text { Beta-agonists } \\
\text { Antimuscarinics } \\
\text { Inhaled corticosteroids } \\
\text { Oxygen } \\
\text { Antihistamines } \\
\text { Leukotriene receptor } \\
\text { antagonists } \\
\text { Mucolytics }\end{array}$ & \\
\hline Gastrointestinal & $\begin{array}{l}\text { Proton pump inhibitors } \\
\mathrm{H} 2 \text { receptor antagonists } \\
\text { Antacids } \\
\text { Laxatives (bulk, osmotic } \\
\text { and stimulant) } \\
\text { Metronidazole } \\
\text { Metoclopramide }\end{array}$ & \\
\hline Antibiotics & $\begin{array}{l}\text { Penicillin } \\
\text { Flucloxacillin } \\
\text { Amoxicillin } \\
\text { Macrolides } \\
\text { Tetracyclines } \\
\text { Trimethoprim } \\
\text { Nitrofurantoin } \\
\text { Vancomycin }\end{array}$ & \\
\hline Nervous & $\begin{array}{l}\text { Paracetamol } \\
\text { Opioids } \\
\text { Carbamazepine } \\
\text { Valproate } \\
\text { Lamotrigine } \\
\text { Levetiracetam } \\
\text { Benzodiazepines } \\
\text { Anti-emetics } \\
\text { Triptans }\end{array}$ & \\
\hline Endocrine & $\begin{array}{l}\text { Metformin } \\
\text { Insulin } \\
\text { Thyroxine } \\
\text { Carbimazole }\end{array}$ & $\begin{array}{l}\text { Other oral } \\
\text { hypoglycaemic } \\
\text { drugs }\end{array}$ \\
\hline
\end{tabular}

Table 1. Core drug list for physician associates

\section{(continued)}

\begin{tabular}{|c|c|c|}
\hline Musculoskeletal & $\begin{array}{l}\text { Non-steroidal anti- } \\
\text { inflammatory drugs } \\
\text { Bisphosphonates }\end{array}$ & $\begin{array}{l}\text { Allopurinol } \\
\text { Colchicine } \\
\text { Methotrexate } \\
\text { Biologics }\end{array}$ \\
\hline Female health & $\begin{array}{l}\text { Combined oral } \\
\text { contraceptive } \\
\text { Progesterone only pill } \\
\text { Emergency contraception } \\
\text { Hormone replacement } \\
\text { therapy }\end{array}$ & \\
\hline Genitourinary & $\begin{array}{l}\text { Alpha blockers } \\
\text { Antimuscarinics } \\
\text { Phosphodiesterase type } 5 \\
\text { inhibitors } \\
\text { 5-alpha reductase } \\
\text { inhibitors (finasteride) }\end{array}$ & \\
\hline Intravenous fluids & $\begin{array}{l}\text { Crystalloids } \\
\text { Colloids }\end{array}$ & \\
\hline Mental health & $\begin{array}{l}\text { Atypical antipsychotics } \\
\text { Selective serotonin } \\
\text { reuptake inhibitors } \\
\text { Lithium } \\
\text { Valproic acid }\end{array}$ & \\
\hline Dermatology & $\begin{array}{l}\text { Benzoyl peroxide } \\
\text { Topical retinoids }\end{array}$ & \\
\hline
\end{tabular}

During their induction week, students were taught how to navigate the British National Formulary (BNF), NICE and Clinical Knowledge Summaries (CKS) to help them build their formulary. Self-directed learning is an effective teaching style for mature students, promotes life-long learning as supported by the CCF and teaches students skills they will use in clinical practice. ${ }^{6}$ In our own clinical work, we regularly use resources to propose treatment plans and medications.

Students are not required to memorise drug doses as drug dosages vary widely dependent on patient and clinical scenario and local guidelines This aligns with teaching on the SGUL clinical pharmacology and Bachelor of Medicine, Bachelor of Surgery (MBBS) programmes. More importantly, students learn how to find dosages quickly and accurately.

\section{Module assessment and activities}

To further ensure curriculum alignment, we redesigned the AP assessment to match the module content with the same breakdown: $70 \%-80 \%$ of the assessment covers pharmacotherapeutics and $20 \%-30 \%$ covers pharmacology and prescribing principles.

The AP exams included 50 single best answer (SBA) questions and three short answer questions (SAQs). The SBAs were in the same format as the national qualifying examination and tested students' application and knowledge of medications, specifically drugs from their formulary, further reinforcing the importance of the SDL component of this module. 


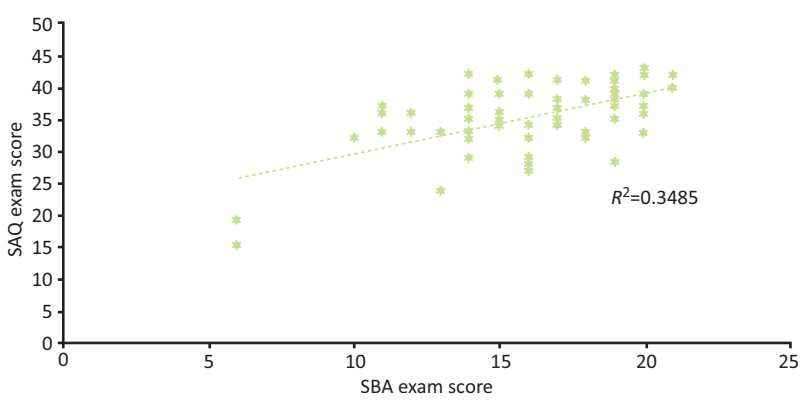

Fig 1. Correlation of Applied Pharmacology formative exam scores. SAQ $=$ short answer question; $\mathrm{SBA}=$ single best answer

We tested a higher level of learning (application of knowledge) with the SAQs. ${ }^{10}$ The questions started with a clinical vignette and students were asked to design patient-centred treatment plans with patient education, thus promoting a more authentic assessment that helped students to bridge the gap between theory and clinical practice. ${ }^{11}$

Recognising that application of knowledge is a difficult skill, we gave our students practice SAQs in the same format as the summative exam. They completed the SAQ individually, and then a discussion board on our virtual learning environment was provided. This encouraged SDL and peer-to-peer teaching, which improves knowledge retention in medical education. ${ }^{12}$

The SAQs also gave us an opportunity to test students using a method other than SBA. Most of the modules in our programme test students through SBA, and objective structured clinical examination. Just as students have different learning styles that need to be addressed, students perform better on different exam styles. ${ }^{13}$ A comparison of our formative SAQ and SBA exam scores showed a low correlation $R^{2}=0.3485$ between students' scores, suggesting that individual students do not perform equally on both exams (Fig 1).

To help them focus their revision, after the formative and summative exams, students are given a breakdown of their scores on the SBA examination, both system-based and questionbased; for example, students are given their percentage score on cardiology, respiratory and gastrointestinal questions and also given their percentage score on side effect, monitoring and mechanism of action questions. We hope this allows them to focus their revision for future examinations, including the national examination.

\section{Technology}

Finally, in response to the COVID-19 pandemic, higher education academies have shifted learning from face-to-face to remote. Students and faculty members have enjoyed the flexibility associated with this approach, and many programmes may opt for a blended approach to learning. This module, unlike clinical examination skills for example, runs very well in a remote environment and will likely continue to do so.

We utilised a combination of pre-recorded and live sessions, with a nearly even 50/50 split. Most case-studies were pre-recorded with a post-session activity or quiz designed to solidify the students' learning. After pre-recorded sessions, we often utilised a discussion board for students' questions.

\section{Conclusion}

Student feedback, our experience in clinical practice and national changes with the regulation of PAs in the UK guided us in designing a more clinically focused AP module. We shifted the module content to have a stronger focus on pharmacotherapeutics, provided a core drug list, encouraged formulary building and assessed high-level application knowledge, all in a completely remote learning environment. Student feedback has shown increased ratings for organisation, engagement and quality. It is currently unclear to what extent AP is taught on PA programmes across the UK. While we recognise the challenges associated with implementing effective AP teaching, we must meet these challenges to benefit our students and ensure patient safety. This module has shown us that we can teach PA students to be prescriber-ready and equip them with skills to be adaptable life-long learners; there is a large SDL component to this module, requiring students to learn the skills to maintain up-to-date knowledge and continue to build their formulary, specific to the field in which they choose to practise. They will be well prepared if PAs are accepted onto V300 courses or will have the skills required if prescribing rights are given to PAs.

As we continue to develop this module, we will keep student experience and patient safety as a focus. We will use student feedback to evaluate the changes we have made. Our students graduate as part of a growing profession and PA community. In future work, we aim to examine the approach to teaching pharmacology to PAs on a national level and compare this to the approach in the USA, where PAs are given legal prescribing rights upon qualification. We also aim to compare our curriculum to that of well-established prescribing qualifications (such as the V300) and compare our assessments to the prescribing safety assessment for foundational school candidates. We welcome the guidance and input from the GMC regarding the level of pharmacology teaching expected in PA programmes and will continue to adapt the module as the PA profession changes.

\section{Supplementary material}

Additional supplementary material may be found in the online version of this article at www.rcpjournals.org/fhj: S1 - Learning objectives of Applied Pharmacology.

\section{Acknowledgements}

The authors would like to thank the lecturers who have helped contribute to the teaching and development of the AP module at SGUL: Emma Baker, Vasa Gnanapragasam, Drew Walker, Azara Janmohamed and Fu Ng.

\section{References}

1 Royal College of Physicians. Who are physician associates? RCP, 2021. www.fparcp.co.uk/about-fpa/who-are-physician-associates [Accessed 8 September 2021].

2 Department of Health. Matrix specification of Core Clinical Conditions for the Physician Associate by category of level of competence. DH, 2012. www.bfwh.nhs.uk/onehr/wp-content/uploads/2016/07/DoH-PACurriculum-Matrix.pdf [Accessed 8 September 2021].

3 General Medical Council. PA and AA regulation 2021. GMC, 2021. www.gmc-uk.org/pa-and-aa-regulation-hub [Accessed 11 May 2021].

4 NHS. Interim NHS People Plan. NHS, 2019. www.longtermplan. nhs.uk/wp-content/uploads/2019/05/Interim-NHS-People-Plan_ June2019.pdf [Accessed 13 May 2021]. 
5 Royal College of Physicians. Physician Associate National Certification and Recertification Exam Information. RCP, 2021. www.fparcp.co.uk/examinations/overview [Accessed 20 May 2021].

6 Lunyk-Child OI, Crooks D, Ellis PJ et al. Self-Directed Learning: Faculty and Student Perceptions. J Nurs Educ 2001:40;116-23.

7 University of Worcester. V300 Independent and Supplementary Prescribing for Nurses: MSAP 4021 And HESC 3020: Guidance for Designated Medical Practitioners. University of Worcester, 2017. www.worcester.ac.uk/documents/DMP-handbook.pdf [Accessed 11 May 2021].

8 Royal Pharmaceutical Society. A Competency Framework for all Prescribers. RPS, 2016.

9 Biggs J. Enhancing teaching through constructive alignment. Higher Education 1996:32;347-64.

10 Bloom BS. Taxonomy of educational objectives: the classification of educational goals. Longmans, Green and Co, 1956.
11 Stein S, Isaacs G, Andrews T. Incorporating authentic learning experiences within a university course. Studies in Higher Education 2004:29;239-58.

12 Rees E, Quinn P, Davies B, Fotheringham V. How does peer teaching compare to faculty teaching? A systematic review and meta-analysis. Med Teach 2016:38;829-37.

13 Leithner A. Do Student Learning Styles Translate to Different "Testing Styles”? Journal of Political Science Education 2011:7;416-33.

Address for correspondence: Brogan N Guest, St George's, University of London, Cranmer Terrace, London SW17 ORE, UK.

Email: bguest@sgul.ac.uk 